\title{
Fordlândia: o empreendedorismo inovador da Ford Motor Company na
} Amazônia brasileira

Daniela Denize Freitas

Mestranda em Administração pela FPL Educacional (Fundação Pedro

Leopoldo/MG), Minas Gerais, Brasil

danedfreitas@gmail.com

Jorge Tadeu de Ramos Neves

Doutorado em Génie Industriel et Gestion de L'innovation Technologique - École Centrale de Paris e Pós-Doutorado em Empreendedorismo e Inovação na Université de Montréal, Canadá. Professor Associado 4 da Escola de Ciência da Informação da Universidade Federal de Minas Gerais e professor permanente do Mestrado Profissional em Administração da Fundação Pedro Leopoldo e professor adjunto 1 do Mestrado em Sistemas de Informação e Gestão do Conhecimento da Universidade FUMEC. Professor convidado e orientador de TCC da Fundação Dom Cabral, Minas Gerais, Brasil jtrneves@gmail.com

Editor Científico: José Edson Lara

Organização Comitê Científico

Double Blind Review pelo SEER/OJS

Recebido em 22.10.2017

Aprovado em 06.11.2017

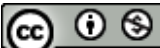

Este trabalho foi licenciado com uma Licença Creative Commons - Atribuição - Não Comercial 3.0 Brasil 


\title{
Resumo
}

Este ensaio tem como objetivo analisar os desafios enfrentados pela Ford Motor Company (FMC) na implementação do empreendimento inovador da cidadeempresa de Fordlândia, em meio à floresta amazônica, no Estado do Pará, bem como conceituar a expressão cidade-empresa, buscando caracterizar o projeto sob a luz do empreendedorismo e da inovação. O trabalho foi produzido a partir de levantamento bibliográfico e documental, utilizando como método de pesquisa a análise de conteúdo. Os resultados da pesquisa revelaram que diversos foram os desafios enfrentados pela FMC, caracterizando o projeto como empreendedor e inovador de grande vulto, do mesmo modo que foi assertiva a utilização da expressão cidade-empresa para designar Fordlândia.

Palavras-chave: Ford Motor Company; Empreendedorismo; Inovação; Fordlândia; Cidade-empresa.

\section{Fordlândia: Ford Motor Company innovative entrepreneurship in the Brazilian Amazon}

\begin{abstract}
This essay aims to analyze the challenges faced by the Ford Motor Company in the implementation of Fordland's innovative enterprise-city enterprise, in the middle of the Amazon rainforest, in the State of Pará, as well as to conceptualize the citycompany expression, seeking to characterize the project under the light of entrepreneurship and innovation. The study was carried out from a bibliographical survey, using as a research method the content analysis. The results of the survey revealed that several challenges were faced by the FMC, but they did not deprive the project of being innovative and entrepreneurial in a great magnitude, and also that it is assertive to use the expression city-company to address Fordlândia.
\end{abstract}

Keywords: Ford Motor Company; Entrepreneurship; Innovation; Fordlândia; Citycompany.

\section{Fordlandia: el emprendedorismo innovador de la Ford Motor Company en la Amazonia brasileña}

\section{Resumen}

Este ensayo tiene como objetivo analizar los desafíos enfrentados por la Ford Motor Company en la implementación del emprendimiento innovador de la ciudad-empresa de Fordlandia, en medio de la selva amazónica, en el Estado de Pará, así como conceptuar la expresión ciudad-empresa, buscando caracterizar el proyecto bajo la luz del espíritu empresarial y la innovación. El artículo fue realizado a partir de 
levantamiento bibliográfico, utilizando como método de investigación el análisis de contenido. Los resultados de la investigación revelaron que diversos fueron los desafíos enfrentados por la FMC, pero que no descaracterizaron el proyecto como emprendedor e innovador de gran volumen, del mismo modo que fue asertiva la utilización de la expresión ciudad-empresa para designar a Fordlandia.

Palabras clave: Ford Motor Company; Emprendedor; Innovación; Fordlandia; Ciudad-empresa.

\section{Introdução}

Atualmente, com os grandes avanços tecnológicos, empreender e inovar são práticas que integram múltiplos fatores que podem ou não promover o sucesso da organização. Para Dornelas (2008), em suma, empreendedorismo é fazer diferente, empregando os recursos disponíveis de maneira criativa, assumir riscos, identificar e buscar oportunidades e inovar.

Nesse sentido, com base em uma rápida retrospectiva pelos séculos XIX e XX, é possível observar que, dentre tantas inovações tecnológicas, destacam-se a descoberta da eletricidade e do magnetismo, a invenção do motor a combustão, que levou ao desenvolvimento da indústria do petróleo e da linha de montagem de automóveis. Essa última é considerada por Tigre (2006) como uma das mais representativas no âmbito tecnológico de processo que a humanidade já empreendeu. Nesses períodos, empreender e inovar eram processos muito mais desafiadores do que os atuais.

De maneira mais específica, considerando o foco desse estudo, empreender e inovar na década de 1920, implementando o projeto Fordlândia, não foi uma tarefa fácil. O Projeto consistiu em montar toda uma estrutura de cidade e de empresa em meio à floresta amazônica e, considerando a época e as dificuldades inerentes ao ambiente, é possível inferir as dificuldades que se apresentaram para a Ford Motor Company.

Diante desse contexto, o questionamento que se faz é o seguinte: quais os desafios enfrentados pela Ford Motor Company (FMC) na implementação do empreendimento inovador da cidade-empresa Fordlândia?

Além da vertente histórica, este ensaio propõe uma análise dos desafios enfrentados pela empresa de Henry Ford ao implementar uma cidade-empresa na 
Amazônia brasileira, conceituar a expressão cidade-empresa e caracterizar o projeto como sendo empreendedor e inovador.

A partir desta introdução, este ensaio apresenta Referencial Teórico sobre o contexto histórico do início da FMC, seguido pelo conceito de cidade-empresa, perpassando pela implementação da cidade-empresa Fordlândia e pela base teórica sobre empreendedorismo e inovação. Na sequência, os dados documentais são apresentados e analisados, com a identificação dos desafios e da caracterização do projeto, e, por fim, estão as Considerações Finais e sugestões de pesquisa.

\section{Referencial Teórico}

O objetivo do arcabouço teórico apresentado nesta seção é proporcionar o embasamento para a discussão acerca dos documentos pesquisados. A contextualização histórica sobre a formação da FMC, a abordagem conceitual acerca dos temas cidade-empresa, inovação e empreendedorismo servirão de referência para as análises ora apresentadas que culminaram nas Considerações Finais sobre este estudo.

\subsection{Contexto histórico - início da Ford Motor Company}

A FMC foi fundada em 1903, com capital inicial de 100 mil dólares, uma semana após a realização de uma corrida de automóveis em que o carro '999', construído por Henry Ford com colaboração de Thomaz Cooper, venceu os concorrentes com uma diferença de três quilômetros em relação ao outro competidor (Ford, 1926).

Inicialmente, Ford foi vice-presidente, desenhista, engenheiro-chefe, inspetor e diretor-geral da empresa. Possuía $25 \%$ das ações, situação que não o agradava. Para ele, era impossível gerir uma empresa em que não possuísse a totalidade das ações. Três anos após a abertura da FMC, Ford tornou-se sócio majoritário com $51 \%$ das ações. Pouco tempo depois subiu para 58\%. Em 1919, seu filho Edsel adquiriu o restante das ações que estavam fora das mãos de Ford (Ford, 1926).

Para Tigre (2006) as inovações resultam em queda de preços e crescimento da produção, o que foi alcançado pela FMC. Seu crescimento foi muito rápido 
produzindo carros denominados de Modelo A, B, C, F, N, R, S e K. Mas Ford perseguia a ideia de um modelo que fosse universal, elegendo o Modelo $T$ pela sua simplicidade. Em 1909, Ford declarou que "só fabricaríamos um único modelo, o T, ajuntando que cada comprador podia pintar o seu da cor que the agradasse, mas que só o receberia preto" (Ford, 1926, p. 67).

Para Ford (1926, p.148),

[era] preferível vender muito com pequeno lucro, do que vender pouco com alto lucro. Isto, além de facilitar as compras a grande número de pessoas permitiria oferecer a muita gente trabalho bem pago, além de estabeleceremse programas fixos, eliminar as estações mortas e prevenir o desperdício, que significa manter uma fábrica a meia produção (Ford, 1929, p.148).

Assim, a empresa lucrava pela inovação no processo de produção em série, que baixava o custo e permitia a Ford reduzir o preço do Modelo $\mathrm{T}$, ampliando seu mercado consumidor e inibindo a concorrência, até as vésperas da crise econômica de 1929 nos Estados Unidos (Grandin, 2010).

Com uma cultura organizacional empreendedora, devido ao espírito de Ford, a empresa produzia desde sua matéria prima ao produto final acabado, sistema denominado de concentração vertical (Szezerbicki, Pilatti, \& Kovaleski, 2004).

Para maior autossuficiência na produção, era necessário produzir sua própria borracha (Sena, 2008). O cartel do látex natural na década de 1920 era inglês, devido ao fato de Henry Wickham, em 1876, ter contrabandeado 70 mil sementes da Hevea Brasiliensis (seringueira) entregando-as para os Reais Jardins Botânicos de Londres, o que serviu de base genética de todas as plantações da borracha em colônias britânicas, francesas e holandesas.

Importante ressaltar que os inimigos naturais (fungos e insetos) da Hevea Brasiliensis não existem na Ásia e nem na África, permitindo uma produção industrial a baixo custo e, assim, a borracha brasileira encontrou um rival comercial levando à queda drástica da produção no Brasil (Romero, 2017; Duarte, 2014; Grandin, 2010; Haag, 2009; Sena, 2008).

Neste contexto, era necessário inovar e Ford buscou empreender na Amazônia brasileira um projeto de plantação de seringueiras e extração do látex em larga escala para se livrar do cartel britânico e das especulações imobiliárias que o impediram de produzir borracha na Flórida de forma industrial, em 1924. (Grandin, 2010; Haag, 2009). 


\subsection{0 conceito de cidade-empresa}

A princípio, se faz necessário justificar teoricamente a utilização da expressão cidade-empresa para designar Fordlândia. Conforme Dias (1999), cidades-empresas são empreendimentos que procuram expandir novas condições técnicas de produção em locais pré-selecionados, influenciando na formação urbana nacional.

Para Oliveira (1999), a expressão cidade-empresa está diretamente ligada ao modelo de planejamento estratégico da organização na cidade, no qual a competitividade com o meio ambiente externo é elemento constitutivo.

Já para Correia (2001), a designação companies towns diz respeito a locais que, a partir da fixação de uma empresa, sofrem modificações geográficas e de infraestrutura, surgindo, além das casas operárias, igreja, comércio, escola, clube, hospital, cinema, fábrica, usina hidrelétrica, serraria, estradas, culturas agrícolas, saneamento básico e equipamentos coletivos.

De acordo com Sena (2008), Fordlândia foi a primeira cidade-empresa edificada na Amazônia. Foi desenvolvida para alcançar o objetivo da FMC e provocou grandes alterações na cultura local, alterando relações de trabalho e da vida de seus habitantes.

\subsection{A implementação da cidade-empresa Fordlândia}

Para o secretário de Ford, Enest Liebold, o melhor local para a seringueira ser cultivada seria na região de sua origem, ou seja, na Amazônia brasileira. Assim ele raciocinou após Ford incumbi-lo de pesquisar sobre o melhor local para o novo empreendimento da FMC, que consistia na produção de látex natural em escala industrial (Grandin, 2010).

José Custódio Alves de Lima era inspetor consular do Brasil em Nova York e recebeu do governo do Estado do Pará autorização para oferecer a Ford toda sorte de incentivos fiscais e vantagens competitivas (Dornelas, 2008), com o intuito de que o capital estrangeiro entrasse na economia nacional, reaquecendo principalmente 0 comércio da borracha (Grandin, 2010).

A FMC já era uma empresa conhecida e possuía escritórios na América Latina desde 1914. Buenos Aires, em 1917, recebeu a primeira unidade de 
montagem da FMC. Entre 1919 e 1920, São Paulo foi a segunda cidade latinoamericana a receber a unidade. Quatro anos após o estabelecimento em terras brasileiras, a FMC já havia vendido 24.250 Modelos T, carinhosamente apelidado de Ford Bigode (Duarte, 2015; Grandin, 2010).

O governador do Estado do Pará, Dionísio Bentes, ao receber informações sobre o interesse da FMC em investir no estado cogitou oferecer gratuitamente à empresa um terreno de 10 milhões de hectares próximo a Belterra. Não o fez porque Carl D.LaRue, botânico enviado ao Brasil por Ford, recomendou outra localidade - 0 vale do rio Tapajós, em Boa Vista, que custou à FMC 125 mil dólares (Duarte, 2015; Grandin, 2010; Sena, 2008).

Ford enviou funcionários para cuidarem dos trâmites legais e burocráticos. Além da posse de terra, a Companhia Ford Industrial do Brasil (CFIB), "teve sua escritura aprovada em outubro de 1927, pela Junta Comercial do Pará, sendo nomeado seu presidente Edsel Ford, filho único de Henry Ford" (Duarte, 2015, p. 4).

Os navios Lake Ormoc e Lake Farge zarparam em direção ao Tapajós em julho de 1928, porém só chegaram em dezembro do mesmo ano devido ao período de estiagem e ao leito de pedra do Rio Tapajós, que impedia os navios de navegarem até $80 \mathrm{~km}$ abaixo de onde planejavam a plantação (Duarte, 2015; Grandin, 2010).

Conforme Grandin (2010), os navios carregavam de tudo: médico, engenheiro eletricista, químico, contador, gerentes. "O Ormoc tinha a bordo bastante ciência, cérebro e dinheiro. O que não tinha era um horticultor, agrônomo, botânico, microbiologista, entomologista, ou qualquer outra pessoa que soubesse de seringueiras silvestres e seus inimigos" (p. 138). Isso confirma a filosofia de Ford de dispensar especialistas. Certa vez afirmou que "alguns dos nossos melhores achados foram devidos a deixarmos os loucos insistirem no que os sábios haviam abandonado" e que "não há em nossas fábricas experts ou peritos, e temos sido forçados a nos desembaraçar de todos que começavam a se ter como tais". (Ford, 1926, p. 82). Para Ford, os especialistas vetavam toda capacidade criativa e inovadora para dar solução aos processos industriais.

Enquanto os navios não chegavam ao vilarejo de Boa Vista, futura cidadeempresa Fordlândia, Blakeley e Villares, funcionários designados por Ford para administrarem o empreendimento, começavam a limpar a floresta utilizando motosserras compradas na região gastando muito combustível para tentar queimar o 
desmate e contaminando o solo e a capacidade de nutrir as futuras mudas de árvores; afinal, não eram especialistas (Grandin, 2010).

Após terem completado a limpeza, até meados de 1929, plantaram 404 hectares, superfície muito inferior do planejamento inicial da CFIB (Sena, 2008).

Os navios, enfim, descarregaram máquinas para a plantação, tais como escavadeira, geradores, tratores, enxadas, pás, britadeira, máquina de fazer gelo, equipamento hospitalar, misturadores de concreto, serraria, prédios pré-fabricados, depósito desmontado, estacas de aço, amianto para tetos, encanamentos, material de escritório, roupas, medicamentos, carne congelada, trilhos, locomotiva, uma grande caixa d'água, apito de fábrica, entre outros, totalizando um milhão de dólares em produtos (Grandin, 2010).

Fordlândia começou a tomar forma de cidade-empresa, visto que foram construídas oficinas, hospital, casas, escolas, cemitério, 'cinema' (uma tela e projetor que passavam filmes norte-americanos), estradas, serraria, restaurantes, campo de futebol, igreja, sistema de abastecimento de água (com hidrantes nas ruas), ferrovia, campo de golfe (para os funcionários com cargos mais altos), salão de bailes, clube com piscina, quadra de tênis, porto, armazéns, creche, emprego, escritório, fábrica, dentre outros, constituíram o empreendimento da FMC na Amazônia (Romero, 2017; Pereira, 2013; Sena, 2008).

A FMC, como qualquer outra empresa, necessitava de mão de obra, tarefa não muito fácil na Amazônia. Ford acreditava que poderia executar sua política de altos salários no Tapajós como incentivo para que os trabalhadores permanecessem no trabalho, tal como motivar para o bom desempenho das atividades.

Entretanto, a rotatividade da mão de obra era alta, visto que a floresta fornecia o alimento e as condições básicas para o trabalhador sobreviver com sua família. Frutas, caça e pesca, tudo estava à disposição na floresta, não havendo um comércio local que pudesse absorver os ganhos dos trabalhadores (Grandin, 2010).

Era cultura vigente adiantar créditos, em vez de pagar salários. Para Oliven (2007), o principal método das economias sem dinheiro se constitui nas 'dádivas', ou seja, produtos que atam todos de uma comunidade num ciclo de trocas de longo prazo, gerando padrões sociais que, consequentemente, geram padrões de trabalho. Nestas comunidades quantificar, ou seja, mensurar as trocas em valores monetários é praticamente impossível. Foi exatamente o que um dos funcionários da 
FMC constatou em Fordlândia ao afirmar que não existia nenhuma escala salarial que pudesse ser fixada (Grandin, 2010).

Mediante essas situações, o fato de Ford implementar a inovação de pagar salários e altos, entre 25 a $35 \%$ acima do salário local, não garantiu uma força de trabalho estável. Outros fatores contribuíram para essa rotatividade, tais como a sazonalidade e o valor salarial acumulado. O primeiro consistia na cultura de que os caboclos trabalhavam por períodos sazonais, acompanhando as chuvas e estiagens ou períodos das colheitas de castanhas. O segundo residia no amontoado de dinheiro que fosse suficiente para que o trabalhador pudesse viver por algum período sem trabalhar (Grandin, 2010).

Apesar desta inovação em meio à floresta, vale ressaltar outras como o apito da fábrica e o cartão de ponto que mudavam o ritmo do trabalhador da floresta, que estava acostumado a trabalhar sob a orientação do sol. Ao nascer, se dava o início das atividades; em seu ápice, descanso, pois era o período mais quente do dia e, ao pôr do sol, dava-se o término das atividades de um dia de trabalho (Grandin (2010).

Considerando essa conjuntura, Lima (2015) afirma que os trabalhadores se tornam operacionais depois de serem usurpados de seus conhecimentos, habilidades e de seus hábitos desenvolvidos pela cultura do cotidiano, sendo subjugados à divisão do trabalho. No Tapajós, nunca se havia ouvido sinos de igreja, menos ainda apito de fábrica!

No final de 1930, Fordlândia finalmente se parecia com uma cidade norteamericana. A denominada Vila Americana possuía luz, jardins e mangueiras. Suas casas eram feitas de madeira, com telas nas janelas e com varandas (Duarte, 2015).

\subsection{Empreendedorismo e Inovação}

Para Szezerbicki, Pilatti e Kovaleski (2004), no âmbito da teoria a inovação é sinônimo de algo novo. Contudo, não faz sentido afirmar que pessoas só passaram a ser inovadoras após a publicação de livros e manifestações teóricas sobre o assunto. Muito do que hoje o mundo industrial e tecnológico proporciona advém de homens tão inovadores e empreendedores como Ford.

No escopo da Administração é sabido que Ford inovou de maneira radical a produção automobilística que alcançava um pequeno e abastado nicho de mercado para uma produção em larga escala industrial, modificando e ampliando seu 
mercado consumidor com o seu famoso Modelo T (Bessant \& Tidd, 2009; Davila, Epstein, \& Shelton, 2007; Szezerbicki, Pilatti, \& Kovaleski, 2004).

Assim, para este ensaio cabe apresentar o perfil de Ford como empreendedorinovador, perpassando pela implementação do seu projeto da cidade-empresa Fordlândia.

De início, Ford não gostava de registrar suas experiências e/ou memorizá-las, nem cobrava que seus trabalhadores memorizassem processos que outros tentaram sem resultados. Ele afirmava que essa busca servia para tolher "o espírito de tentar sempre, e o fato de que um homem foi mal sucedido numa tentativa não implica que outro o seja" (Ford, 1926, p. 82). Terra et al. (2007) comungam deste princípio de Ford ao afirmarem que muito planejamento pode enfraquecer o poder da inovação, fenômeno denominado de paralisia de análise.

Para Bessant \& Tidd (2009) pessoas empreendedoras possuem boas redes de relacionamentos com intuito de absorver conhecimento e informações para alcançar seus objetivos. Ford possuía essa característica, visto que detinha um seleto, inovador e criativo círculo de amigos, ressaltando-se Heber Hoover (secretário do comércio e presidente dos EUA entre 1929-1933), Thomas Edison (sua mais famosa invenção foi a lâmpada incandescente comercializável) e Harvey Firestone (fundador da Firestone Tire and Rubber Company).

Hoover alertava os fabricantes americanos da perigosa dependência do mercado europeu em relação à borracha natural, tendo incentivado os industriais para que investissem na produção na América Latina.

Thomas Edison tentava desenvolver o que chamou de 'borracha de guerra', produto alternativo utilizando matéria prima sintética ou orgânica, feita de serralha ou arnica. Seu empenho era apoiado por Ford e Firestone, afinal tinham grande interesse neste projeto; caso alcançasse o sucesso conseguiriam quebrar o cartel britânico sobre a borracha (Grandin, 2010).

Firestone, em 1923, havia organizado uma conferência com os maiores industriais da época com intuito de resolver o problema do cartel britânico. Somente Hoover e Ford apoiaram a ideia da borracha "sob a bandeira americana" (Grandin, 2010, p. 36).

As discussões sobre a questão do látex se estenderam entre os dois empresários. Ford ouvia o aranzel de Firestone que por fim esbravejou "plante suas 
próprias seringueiras" (Grandin, 2010, p. 38). É bem provável que esta frase tenha provocado em Ford "lampejos repentinos que acabam por trazer a luz algo inédito" (Dornelas, 2008, p. 17).

A impulsividade promove fragilidade nos processos iniciais dos negócios e para Bessant \& Tidd (2009) pessoas empreendedoras e inovadoras devem identificar, avaliar e refinar uma ideia antes de investirem para transformá-la em um conceito de negócio.

Hoover havia identificado um gap no mercado da borracha, visto que havia produção industrial na Ásia e na África, mas no continente originário da Hevea Brasiliensis, ainda não. Portanto, o problema já havia sido identificado - a necessidade de tornar a FMC independente na produção do látex e existia uma lacuna, uma oportunidade no mercado (Rossi \& Cozzi, 2010) - produzir na América Latina. Ford avaliou e refinou a possibilidade de extrair o próprio látex.

Era necessário correr o risco e esta era outra característica de Ford. Ele não teve receio em arriscar na produção de látex e, para Terra et al. (2007) e Bessant \& Tidd (2009), o risco é um aspecto inerente à inovação e, portanto, para inovar é importante arriscar. Tentativas, fracassos ou sucessos são componentes que mantem a roda da inovação girando.

Em 1924, a FMC promoveu um experimento na Flórida plantando seringueiras para averiguar se poderiam extrair látex em escala industrial. Contudo, para a organização, produzir borracha na América Latina era bem diferente do que produzir carros. Para Bessant e Tidd (2009), essa alteração no contexto da produção é caracterizada como inovação de posição que, para a FMC já não era novidade, uma vez que fabricava aeroplanos, maquinário, tratores, vidros, força elétrica, papel, cimento, rádio, turbinas entre outros (Ford, 1927).

De acordo com Dornelas (2008) as oportunidades de inovação podem ser salientadas como nova plataforma que consiste na tomada de decisão da empresa de entrar em mercados e negócios totalmente originais para ela, pleiteando mudanças de processo. Já na percepção de Oliveira e Cruz (2016), inovação é um processo de interatividade de informações advindas de diversos campos distintos. Além disso, é também um processo com que a empresa, pessoas e sistemas lidam pela primeira vez.

Conforme o contexto identificam-se três fatores que para Bessant e Tidd (2009) destacam-se como principais para inovação: (i) geração de novas ideias que 
consiste, entre outros conceitos, em um conjunto de ideias pré-existentes advindas de modelos alternativos que, futuramente, poderão ser explorados; (ii) seleção das melhores ideias, que devem ser experimentadas, colocadas em prática para avaliar se são as melhores e se vale a pena ou não investir nelas; e (iii) implementação da nova ideia, ou seja, transformar a ideia em ação, concretizá-la. Esse é um processo difícil, pois não se trata apenas de uma questão de gestão de projetos, mas de apoiar-se em condições de grande incerteza.

Para o empreendedor é importante analisar as vantagens competitivas. Quando Ford pediu ao seu secretário que encontrasse o melhor local para plantar seringueira, decerto o empresário quis dizer que era para encontrar um lugar que proporcionasse oportunidades na América Latina para dar início ao seu empreendimento. Não somente o local é importante para o empreendedor, mas as condições das quais o projeto se desenvolverá, ou seja, as vantagens que a empresa poderá aproveitar (Dornelas, 2008).

O. Z. Ide e W. L. Reeves Blakeley foram os funcionários encarregados de iniciarem uma negociação com o governo do Estado do Pará sobre concessão de terras e, concomitantemente, representavam os interesses da FMC. Portanto, exigiram

o direito de exploração da madeira e reservas minerais, direito de construção de uma ferrovia e pistas de pouso, de erigir qualquer tipo de edificação sem supervisão do governo, abrir bancos, organizar uma força policial privada, dirigir escolas, extrair energia de quedas d'água, represar o rio de qualquer maneira necessária. Isenção de impostos de exportação sobre quaisquer produtos que a plantação pudesse enviar ao exterior (Grandin, 2010, p. 116).

Além das exigências impostas no contrato pelos representantes da FMC, o governo do Pará concedeu à empresa mais de um milhão de hectares, pelo valor de 125 mil dólares. A outra metade eram terras públicas que foram repassadas à FMC gratuitamente. A única exigência do governo paraense foi que, em doze meses, deveriam ser plantados no mínimo 400 hectares de seringueira, demostrando, assim, que o interesse da FMC em produzir látex não era falso, mascarando o possível real interesse de prospecção de ouro, prata e petróleo na região (Grandin, 2010).

Estas concessões no contexto podem ser consideradas vantagens competitivas, uma vez que, a longo prazo, o objetivo da FMC era reduzir o preço da 
matéria prima - látex - o que, consequentemente, desembocaria na redução do custo do Modelo T, refletindo essa diminuição no preço final para o consumidor, ampliando as vendas.

Dois autores confirmam a estratégia da FMC. Para Dornelas (2008), a empresa deve saber usufruir de "uma regulamentação governamental, uma concessão, um contrato de longo prazo" (p. 88), uma vez que estas vantagens podem ser privilégios que promovem o diferencial sobre a concorrência e Maximiano (2011) afirma que a partir do baixo custo dos recursos e eficiência na produção, ocorre redução no custo e, por conseguinte, diminui o preço do produto final.

Transformar a floresta em uma cidade era um empreendimento de grandes proporções, com altos riscos e, normalmente, grandes projetos demandam altos recursos financeiros. Conforme Dornelas (2008), quando projetos inovadores apresentam altos riscos, mercado indefinido e com prazos de retorno dubitável, é recomendável que se crie uma nova empresa com o processo gerencial independente da empresa-mãe. De fato isso foi feito em 1927, quando foi criada a Companhia Ford Industrial do Brasil (CFIB), mas Fordlândia foi totalmente gerenciada pela empresa-mãe.

Esse não distanciamento da empresa-mãe afetou bastante o desenvolvimento de Fordlândia, posto que muitos processos e valores seguidos e considerados padrões pela empresa-mãe sufocaram a criatividade, principalmente a capacidade de adaptação do novo empreendimento às circunstâncias locais, visto não terem sido respeitadas as especificidades culturais da região (Dornelas, 2008; Davila, Epstein \& Shelton, 2007).

Bom exemplo desta interferência foi a construção de mais de 100 casas de trabalhadores feitas de adobe com teto de palha e piso de terra batida, bons materiais e arquitetura que evitavam o calor excessivo e a entrada de insetos. Porém, os dirigentes da FMC em Dearbon (empresa-mãe) não ficaram satisfeitos com os tetos de palha e com a estrutura das casas. Ordenaram que todas fossem trocadas por casas de madeira, cobertas por pranchas (metal revestido de amianto) e o piso de cimento ao estilo Meio-Oeste. O funcionário da FMC responsável pelas construções tentou argumentar que os nativos gostaram das casas com os tetos de palha, mas não adiantou. A ordem foi cumprida e, ao final de 1933, mais de duzentas casas 'modernas' tinham sido construídas. Para Carl LaRue, as casas eram "fornos de ferro galvanizado" (Grandin, 2010, p. 278). 
Além das importantes e necessárias estruturas enviadas pela empresa-mãe (FMC), a CFIB não podia dispensar os recursos financeiros que chegavam de forma irrestrita, ou seja, o empreendimento foi autofinanciado (Bessant \& Tidd, 2009).

Ainda para Bessant e Tidd (2009), existem estágios de desenvolvimento com diferenças financeiras, constituindo-se em financiamento inicial para lançamento, financiamento de segundo ciclo para desenvolvimento inicial e crescimento, financiamento de terceiro ciclo para consolidação e crescimento, e por fim, maturidade e saída. Os autores destacam a possibilidade de reestruturação financeira a cada ciclo em três anos. No contexto da produção do látex na Amazônia, estes ciclos foram maiores, totalizando dezessete anos de tentativas e erros, culminando num empreendimento milionário sem retorno financeiro almejado.

Fordlândia, em uma análise superficial, apresentou traços do empreendedorismo social. Bessant e Tidd (2009) afirmam que os empreendimentos sociais buscam gerar valor social, em vez de lucros. Nesta vertente, os empreendedores procuram melhorar a qualidade de vida e proporcionar acesso de grupos desfavorecidos a recursos básicos. São caracterizados pela ambição e tratam de quadros de pobreza e desigualdades. São motivados por uma missão em que o principal objetivo é gerar valor social, sendo a riqueza um valor secundário. São perseverantes e estratégicos, atuam com situações em que os demais desmerecem. São talentosos, criativos e inovadores para solucionar problemas, principalmente para angariar recursos que financiem projetos deste perfil. São voltados para resultados, desejam o sucesso do empreendimento (Bessant \& Tidd, 2009).

Mas, dialogando com o contexto da implementação da cidade-empresa e, a despeito de toda estrutura desenvolvida, Fordlândia apresentava problemas básicos, estruturais e culturais.

As famílias eram inspecionadas por equipes de saneamento que averiguavam latrinas, cozinhas, certificando se roupas estavam sendo lavadas e se currais estavam sendo mantidos secos e limpos. Foi imposto aos trabalhadores que comessem alimentos enlatados norte-americanos, considerados por Ford mais saudáveis, substituindo uma cultura alimentar baseada na farinha de mandioca, na caça e na pesca (Duarte, 2015). 
As creches, o hospital, as escolas, a igreja, o salão de baile, o 'cinema', o clube e demais propostas de entretenimento não podem ser avaliadas como empreendimento social, dado que o interesse da FMC era de criar e manter alguma ligação entre os trabalhadores, fixando-os na cidade, produzindo e, por conseguinte, diminuindo a rotatividade e a labuta dos encarregados em recrutarem novos trabalhadores e treiná-los; para Ford isso era desperdício de tempo e, consequentemente, de dinheiro. Portanto, o interesse não era de uma melhoria social, mas o que se visava era o lucro que a mão de obra poderia proporcionar. Por isso a hipótese de caracterizar Fordlândia como um empreendimento de cunho social pode ser descartada.

Ainda para Grandin (2010), o modelo das casas era inadequado devido ao calor e aos insetos. A localização da plantação, muito próximo das margens do rio, favorecia o aparecimento de fungos devido ao alto índice de umidade causada pela neblina, principalmente pela manhã. A maneira inovadora para a natureza da Hevea Brasiliensis, em que os oito mil metros quadrados de seringueiras foram plantadas, perfiladas, retirando a vegetação nativa, favoreceu a proliferação incontrolável do Microcylus ulei, que provoca a doença conhecida como mal das folhas. As copas das árvores muito próximas facilitam a contaminação (Furtado, Menten, \& Passos, 2008).

As seringueiras na Amazônia se desenvolvem melhor quando ficam afastadas uma das outras. Para cada 4 mil metros quadrados devem existir duas ou três árvores apenas, reduzindo-se a propagação dos fungos e insetos que se alimentam das folhas (Grandin, 2010).

Para Ford (1926, p. 204), "o fracasso devia estar previsto e ser um estímulo para persistir". Neste sentido, Dornelas (2008), uma das importantes referências no tema do empreendedorismo, afirma que reconhecer que o ato de falhar é crítico é muito importante. A falha não pode ser entendida como sinônimo de incompetência e deve ser avaliada como aprendizado e progresso. Dar credibilidade a certas falhas pode contribuir na busca de oportunidades, assumindo-se riscos. Contudo uma falha contínua deve ser evitada e punida.

As falhas em Fordlândia perpetuaram-se desde sua fundação, em 1928, até 1933. Porém, para a cultura organizacional da FMC, a cidade-empresa nos trópicos não era vista como fiasco. Um dos funcionários escreveu para os dirigentes da FMC em Dearborn afirmando que "todo projeto do Sr. Ford ainda está em fase 
experimental - que seu experimento é tanto sociológico quanto industrial" (Grandin, 2010, p. 271).

No entanto, o projeto foi reformulado começando tudo do zero: novas contratações, construções, permissão para estabelecimentos comerciais. Refizeramse as casas dos trabalhadores, pavimentaram-se e nomearam-se ruas. Quebrando a filosofia de Ford sobre consultar especialistas, os dirigentes da empresa-mãe inovaram, tendo mandado para Fordlândia um especialista, o botânico James R. Weir, que dirigia pesquisas em Sumatra na plantação da Goodyear Tire Company.

Ao chegar a Fordlândia, Weir solicitou a troca de 202 mil hectares da Fordlândia por uma área inexplorada, Belterra, para começar uma nova plantação com plantas geneticamente modificadas, mais resistentes aos fungos e insetos. (Pereira \& Leite, 2011).

Em 1934, Ford, aceitando os conselhos do especialista, optou pelo abandono da plantação que, até aquele momento, nunca havia exportado borracha natural para a FMC (Pereira \& Leite, 2011; Sena, 2008).

De acordo com Dávila, Epstein e Shelton (2007), as histórias de aprendizado são importantes para se analisarem ações, pessoas ou eventos, procurando entender as causas que promoveram o fracasso ou o sucesso, não atribuindo a culpa, mas aprendendo a partir do compartilhamento das experiências. Seguindo este raciocínio, Dornelas (2008) afirma que mudar é bom, desde que tenha propósito de melhoria. É uma oportunidade para a organização olhar para os processos de maneira diferente, excluindo as dificuldades que impedem o sucesso do projeto.

Belterra produzia apenas 178 quilos de látex por hectare. A decisão de encerrar o empreendimento coube ao neto de Ford, Henry Ford II, pois Edsel faleceu em 1943. Ford II vendeu Fordlândia e Belterra ao governo brasileiro por 244 mil e 200 dólares, apesar de todo o empreendimento ter sido avaliado em 8 milhões de dólares, fora os 20 milhões em investimentos realizados.

A FMC retirou-se das propriedades da América Latina em novembro de 1945, deixando para trás toda a estrutura da cidade-empresa Fordlândia, a qual Henry Ford nunca visitou. Ele veio a falecer dois anos depois (Grandin, 2010).

Conforme Maximiano (2011), o encerramento de um projeto deve ser estabelecido antes mesmo do seu início efetivo. Isso ocorre quando há definições cíclicas no projeto. Para o autor, ao encerrar-se um projeto deve haver entrega, 
demonstração e avaliação dos resultados. Dessa forma, como no projeto da cidadeempresa de Fordlândia não houve definições cíclicas, o encerramento foi da mesma maneira que começou, sem planos claramente pré-definidos.

\section{Procedimentos Metodológicos}

Na sequência será apresentada a metodologia empregada neste ensaio.

É importante ressaltar que não há ciência sem o emprego de métodos científicos e que métodos são atividades sistemáticas e racionais que, com maior segurança, permitem alcançar conhecimentos válidos e verdadeiros, detectando erros e auxiliando as decisões do cientista (Marconi \& Lakatos, 2010).

Metodologicamente, o ensaio pautou-se por uma pesquisa descritiva de abordagem do tipo qualitativa, com levantamento bibliográfico e documental (Gil, 2002; Figueiredo, 2007) em livros e artigos, utilizando como método de pesquisa análise de conteúdo e documental.

A abordagem do tipo qualitativa é aquela que "pode ser checada por meio de exame detalhado da literatura e pela comparação das observações colhidas com aquelas da literatura" (Clemente \& Jeunon, 2012, p. 68).

Para Minayo (2007), o estudo qualitativo incorpora as questões do significado e intencionalidade como inerentes aos atos, às relações e às estruturas sociais, sendo estas últimas adotadas tanto no seu advento quanto na sua transformação, como construções humanas (como citado em Otenio et al., 2014).

Análise de conteúdo foi utilizada para analisar os dados obtidos e, segundo Bardin (2009), é uma técnica que busca descrever o conteúdo emitido na comunicação por meio verbal ou por textos.

Para Silva e Fossá (2015), a análise de conteúdo perpassa por diversas fontes de dados como notícias de jornal, discursos políticos, cartas, anúncios, relatórios oficiais, entrevistas, fotografias, revistas, relatos autobiográficos, artigos, livros entre outros.

\section{Apresentação e Análise dos Resultados}

Por meio deste ensaio, buscou-se analisar os desafios enfrentados pela FMC na implementação do empreendimento inovador da cidade-empresa Fordlândia, 
conceituando a expressão cidade-empresa e caracterizando tal projeto à luz dos conceitos de empreendedorismo e inovação.

O estudo apresentou uma série de desafios enfrentados pela FMC. O primeiro pode ser considerado tanto um problema, quanto um impulsionador: a existência do cartel britânico que aumentaria o preço do látex, prejudicando os industriais dependentes desta matéria-prima. Entretanto, despertou a necessidade de inovar e empreender em um negócio até então novo para a FMC, que consistia em plantar seringueiras na América Latina de forma industrial, gap pontuado por Hoover. Era, portanto, algo novo que poderia ser realizado.

A organização buscou uma solução viável para equacionar o problema e, assim, a FMC enviou ao Brasil funcionários para vasculharem a região amazônica em busca de uma localidade que proporcionasse diversos tipos vantagens. Neste processo da localização do terreno, o empreendimento contou também com as vantagens e incentivos fiscais proporcionados pelo governo do Estado do Pará. Neste contexto, os desafios foram de pequena envergadura em comparação aos demais.

Para grandes projetos, existem grandes riscos, mas os retornos podem compensar os altos investimentos. A partir do momento em que uma empresa assume grandes riscos, ela pode ser caracterizada por deter alto nível empreendedor e inovador. Para Ford (1927, p. 59)

existem agora 88 fábricas, das quais 60 nos Estados Unidos e 28 no estrangeiro. Nenhuma delas fabrica um automóvel por completo. Das fábricas americanas 24 são exclusivamente manufatoras e 36 , de montagem ou mistas. Estamos com a seguinte linha de indústrias, todas relacionadas a do motor: aeroplanos, mineração de hulha, manufatura de coke, subprodutos de manufatura, fabrico de instrumentos, fabrico de maquinário, de trucks de carro e tratores, de vidro, couro artificial, fios de cobre, fordite, tecidos, baterias e geradores, papel, cimento, carrocerias de auto, força elétrica, água filtrada, farinha, cinema, hospital, agricultura, rádio, impressão, fotografia, forja, cultura de linho, turbinas, locomotivas elétricas, indústria florestal, moagem, olarias, destilação de madeira, produtos hidroelétricos, armazéns de secos e molhados, de calçado, de fazendas, de carne, estradas de ferro, escolas, navegação marítima ou em lago, tratores e automóveis (Ford, 1927, p. 59).

Assim, percebe-se que produção de látex não entrava na descrição de Ford, apresentando mais uma inovação de posição da FMC. 
Outro grande desafio foi a qualidade e quantidade de mão de obra. A política dos altos salários praticada pela FMC nos EUA não obteve muito sucesso no Brasil, uma vez que a população cabocla estava familiarizada com a cultura da troca e dos adiantamentos da renda, além de obter da floresta produtos para subsistência. Neste contexto, foi desafiador também disciplinar o trabalhador ao tempo do apito da fábrica e da produção, visto que eles seguiam o tempo do sol e as sazonalidades.

A criação da CFIB foi uma iniciativa empreendedora e inovadora, mas foi um processo desafiador para os dirigentes de Fordlândia colocarem em prática os valores e a cultura impostos pela empresa-mãe localizada em Dearbon. Devido ao vulto da FMC, recursos financeiros não faltavam; portanto, dinheiro não era problema e, muito menos um desafio para os gerentes da Fordlândia, visto que a empresa-mãe não media esforços para financiar o projeto.

O empreendedorismo social decerto não aconteceu em Fordlândia e Belterra, pois não foi respeitada a cultura local da população, bem como suas experiências e seu modo de viver, sendo o principal objetivo da FMC evitar abandono dos postos de trabalho pelos trabalhadores e novos treinamentos que, para Ford, significavam desperdício e prejuízo financeiro.

Apesar disso, Fordlândia, a partir das modificações do ambiente por meio das construções, estrutura realizada e pela fixação da empresa no mesmo local, pode ser caracterizada como uma cidade-empresa.

Por falta de especialistas, seguindo a filosofia de Ford, outro grande desafio foi a plantação das seringueiras.

Com conhecimentos empíricos, por meio de tentativas e erros, os idealizadores do projeto presumiram que o experimento que realizaram na Flórida e a partir das observações das plantações na Ásia e África seriam experiências suficientes para colocarem em prática o projeto da produção do látex em larga escala no berço da Hevea Brasiliensis, mas estavam enganados. Foram necessários seis anos para perceberem que Fordlândia não saíra como planejado. Da mesma forma, como o perfil da organização era de alta inovação e empreendedorismo, inovaram na contratação de um botânico e empreenderam em um novo território. Neste sentido, aproveitaram as falhas procurando aprender com elas. Assim foi feito. Belterra produziu enfim látex, contudo numa quantidade muito inferior ao esperado.

Não foram encontradas grandes dificuldades no encerramento do empreendimento, porém o prejuízo foi contabilizado. No entanto, para a envergadura 
da FMC, talvez esse prejuízo não tenha afetado a empresa-mãe que Henry Ford criou, visto que Fordlândia e Belterra, nesta avaliação, podem ter sido apenas um teste.

Portanto, por meio destas análises, os desafios enfrentados pela FMC na implementação da cidade-empresa Fordlândia foram vários e distintos; entretanto não desqualificaram o caráter empreendedor-inovador do projeto, mesmo porque foram colocadas em prática diversas inovações empreendedoras ao longo do período.

\section{Considerações finais}

Muitos e diversificados foram os desafios enfrentados pela FMC na implementação da cidade-empresa Fordlândia. Mesmo assim, a cultura empreendedora-inovadora da empresa e de Ford não se deixou abater e, ao longo do processo, conforme as necessidades, diversas inovações foram sendo colocadas em prática.

Era inovador porque a empresa teve que enfrentar um ambiente desconhecido, bem como teve que lidar com uma planta que exigiu de seus produtores respeito às suas características de cultivo.

Deve ser ressaltado que, para a FMC, criar uma cidade não era um projeto novo, já que outras cidades-empresas foram desenvolvidas nos EUA, como por exemplo em Michigan. No entanto, foi um projeto inovador, uma vez que foi criada uma cidade-empresa nos trópicos, com a proposta de produzir látex.

A partir do exposto, pode-se afirmar que é necessário ter cautela quanto a inovar e empreender, pois nem sempre um processo inovador de sucesso em um determinado ambiente poderá ter o mesmo efeito em outro. Certas estruturas, como cultura local, experiências e valores humanos devem ser respeitadas e trabalhadas concomitantemente com o saber científico para alcançar o sucesso.

Fordlândia deixa este legado e serve como exemplo para administradores e empreendedores atuais que desejam inovar em projetos de grande vulto. Este ensaio também pode contribuir para ampliar o conhecimento sobre o assunto nos meios acadêmicos 
A dificuldade encontrada para a elaboração deste ensaio foi o pouco material sobre Fordlândia sob a ótica do empreendedorismo e da inovação. Boa parte dos artigos encontrados sobre Fordlândia concentram-se na área da História, Ciências Sociais e Biológicas.

Mensurar o grau de empreendimento e inovação da FMC durante a implementação da Fordlândia é uma sugestão para trabalhos futuros, bem como avaliar se o mesmo projeto tem características que possam permitir denominá-lo como uma startup.

\section{Referências}

Bardin, L. (2009). Análise de conteúdo. Lisboa: Portugal, Edições 70, LDA.

Bessant, J.; Tidd, J. (2009). Inovação e Empreendedorismo. Porto Alegre: Bookman.

Clemente, F. A. S., \& Jeunon, E. E. (2012). A percepção dos jovens sobre a imagem organizacional da Companhia Vale e o poder simbólico manifesto nos discursos. Teoria e Prática em Administração, 2(1), 56-85.

Correia, T. B. (2001, maio). De vila operária a cidade-companhia: as aglomerações criadas por empresas no vocabulário especializado e vernacular. Revista Brasileira de Estudos Urbanos e Regionais (4), 83-90.

Davila, T.; Eptein, M. J.; Shelton, R. (2007). As Regras da Inovação. Porto Alegre: Bookman.

Dias, L. C. (1999, janeiro - julho). Resenha do livro Cidade-empresa: presença na paisagem urbana brasileira. Cadernos IPPUR, XIII(1), 217-219.

Dornelas, J. C. A. (2008). Empreendedorismo Corporativo. Como ser empreendedor, inovar e se diferenciar na sua empresa (2a ed.). Rio de Janeiro: Elsevier.

Duarte, A. M. Jr. (2015, janeiro-junho). Fordlândia e Belterra: As cidades de Henry Ford na Amazônia. Revista Brasileira de Casos de Ensino em Administração. GVCasos, 5(1), 1-13.

Figueiredo, N. (2007). Método e Metodologia na pesquisa científica (2a ed.). São Paulo: Yendis.

Ford. H. (1926). Minha Vida e Minha Obra (M. Lobato, Trad.). São Paulo: Companhia Editora Nacional.

Ford. H. (1927). Hoje e Amanhã (M. Lobato, Trad.). São Paulo: Companhia Editora Nacional. 
Furtado, E. L., \& Menten, J. O. M.; Passos, J. R. (2008, março - abril). Intensidade do Mal das Folhas em plantas jovens e adultas de seis clones de seringueiras na região do Vale do Ribeira. Tropical Plant Pathology, 33(2), 130-137.

Gil, A. C (2002). Como elaborar projetos de pesquisa. São Paulo: Atlas.

Grandin, G. (2010). Fordlândia. Ascensão e queda da cidade esquecida de Henry Ford na selva. Rio de Janeiro: Rocco.

Haag, C. (2009, abril). A pastoral americana. Henry Ford tentou, sem sucesso, produzir borracha e utopias na Amazônia. Pesquisa FAPESP (158), 16-21.

Lakatos, E. M., \& Marconi, M. A. (2010). Fundamentos de Metodologia Científica (7a ed.). São Paulo: Atlas.

Lima, A. A. M. de. (2015). Configuração da imagem da auditoria interna: um Estudo com Múltiplos olhares. (Dissertação Mestrado em Administração. Fundação Pedro Leopoldo - FPL, Pedro Leopoldo, MG, Brasil).

Maximiano, A. C. A. (2011). Administração para empreendedores (2a ed). São Paulo: Pearson Prentice Hall.

Oliveira, F. L. (1999, janeiro-julho). Metáfora Cidade-Empresa no Planejamento Estratégico de Cidades. Cadernos IPPUR, XIII(1), 141-162.

Oliveira, L. C. S. \& Cruz, J. E. (2016). Estado da Arte: a relação entre inovação, empreendedorismo e desempenho. Anais do $5^{o}$ Simpósio Internacional de Gestão de Projetos, Inovação e Sustentabilidade, São Paulo, SP, Brasil

Oliven, R. G. (2007, julho - dezembro). The world of goods twenty years later. Horizontes Antropológicos, 13(28), 17-32.

Otenio, M. H., Santos, G. M., Galvão, D. F., Dupas, F. A., \& Assad, M. L. R. C. L. (2014.). Metodologia do Discurso do Sujeito Coletivo na representação sócia da Bacia Hidrográfica. Caderno Prudentino de Geografia, 36(Volume especial), 4466.

Pereira, J. C. M. (2013). Cidade na floresta: Belterra, a experiência da plantation de seringa de Henry Ford na Amazônia brasileira (1934-1945). Avances del CESOR, $X(10), 129-150$.

Pereira, J. C. M., \& Leite, M. S. P. (2011, dezembro). A "fala do desenvolvimento" em Belterra e a transformação do lugar em dois contextos de modernização. Novos Cadernos NAEA - UFPA, 14(2), 197-217.

Romero, S. (2017, fevereiro). Deep in Brazil's Amazon, Exploring the Ruins of Ford's Fantasyland. New York Times. Recuperado em 04 abril, 2017, de http://www.nytimes.com/20 07/02/20/world/americas/deep-in-brazils-amazon-exploringthe-ruins-of-fords-fantasyland.html. 
Rossi, A., \& Cozzi, A. (2010, março). A cultura empreendedora como aliada da inovação. Revista DOM, (11), 24-31.

Sena, C. (2008, julho-dezembro). Fordlândia: breve relato da presença americana na Amazônia. Cadernos de História da Ciência - Instituto Butantan, IV(2), 89-98.

Silva, A. H., \& Fossá, M. I. T. (2015). Análise de conteúdo: exemplo de aplicação da técnica para análise de dados qualitativos. Qualitas Revista Eletrônica, 16(1), 114.

Szezerbicki, A, S., Pilatti, L. A., \& Kovaleski, J. L. (2004, dezembro). Henry Ford: a visão inovadora de um homem do início do século XX. Publicatio - UEPG Ciências Humanas, Ciências Sociais aplicadas, Linguística, Letra e Artes, 12(2), 105-110.

Terra, J. C. C. (Org.).(2007). Inovação: quebrando paradigmas para vencer. São Paulo: Saraiva.

Tigre, P. B. (2006). Gestão da Inovação: A Economia da tecnologia no Brasil. Rio de Janeiro: Campus. 